\title{
Impact of Ionic Strength on Colloid Retention in a Porous Media: A Micromodel Study
}

\author{
Safna Nishad \\ sn1518223@qu.edu.qa \\ Department of Civil and Architectural Engineering, Qatar University, Doha, Qatar \\ Riyadh I. Al-Raoush \\ riyadh@qu.edu.qa \\ Department of Civil and Architectural Engineering, Qatar University, Doha, Qatar
}

\begin{abstract}
Release of deposited colloids in the soil porous media during two-phase flow poses potential health hazard due to the facilitated transport of contaminants towards groundwater reservoirs. Considerable uncertainties exist concerning the impact of ionic strength on pore-scale mechanisms of colloid mobilization during transient flow. This study aims to investigate the effect of ionic strength on colloid retention and mobilization using a glass micromodel. The behavior of Carboxylate modified Polystyrene latex particles of $5 \mu \mathrm{m}$ diameter in saline solution (i.e., $100 \mathrm{mM} \& 1 \mathrm{mM}$ of $\mathrm{NaCl}$ at $\mathrm{pH}$ 10) was visualized with an optical microscope during saturated and twophase flow. We found that colloid aggregation and attachment on Solid-Water Interfaces (SWI) was increased with increase in ionic strength. CO2 injection into the saturated micromodel mobilized the previously attached colloids on SWI, retained at the GasWater Interfaces (GWI) due to capillary forces and thus were transported through the micromodel. Imbibition mobilize colloids from GWI and are transported or reattached on SWI depending on the ionic strength of pore water. The greater adhesive forces of colloids at higher ionic strength was resulted in thin film attachment during drainage and reattachment of colloids mobilized from GWI on SWI during imbibition. The acquired images showed the application of a micromodel for the visualization of colloid retention and re-mobilization through the porous media.
\end{abstract}

Keywords: Colloid retention; Two-phase flow; Drainage and imbibition; Micromodel study

\section{INTRODUCTION}

Colloid transport and retention in soil porous media has recently attracted significant attention due to its potential impact on various applications including ground water recharge and contamination, filtration in water and wastewater treatment processes (Crist, Zevi, Mccarthy, Throop \& Steenhuis, 2005; Saiers \& Lenhart, 2003; Sirivithayapakorn $\&$ Keller, 2003). Although the colloids themselves rarely pose environmental challenge, the colloid facilitated transport of pathogens and other contaminants occur naturally within the soil and transmit towards the ground water aquifers through the vadose zone (Syngouna \& Chrysikopoulos, 2015; Torkzaban, Tazehkand, Walker \& Bradford, 2008). Rapid infiltration during rainfall can significantly reduce the ionic strength of pore water, which decreases the colloid retention on Solid-Water Interfaces (SWI) and facilitate its 
transport through the soil (Mesticou, Kacem \& Dubujet, 2014, 2016; Pazmino, Trauscht $\&$ Johnson, 2014). In addition, higher colloid retention was reported in unsaturated porous media with increase in ionic strength (Mitropoulou, Syngouna \& Chrysikopoulos, 2013; Zevi et al., 2009; Zhuang et al., 2010). However, the effect on mobilization of the colloid from SWI by the moving Gas-Water Interfaces (GWI) with the changes in ionic strength has not been addressed before.

Previous studies on mobilization of deposited colloids in the porous media reveal the influence of changes in fluid chemistry and flow rate in saturated porous media and transients in flow in unsaturated systems (Molnar, Johnson, Gerhard, Willson \& O'Carroll, 2015; Syngouna \& Chrysikopoulos, 2015). The force balance considerations on the attached colloids indicate mobilization occur from the solid surface when the detachment force exceed the adhesion force between colloid and the surfaces. This can occur during low salinity flooding (reduced adhesive forces) and at higher injection rates (increased hydrodynamic drag) in saturated flow systems (Gao et al., 2008; Lazouskaya et al., 2011, 2013).

Several laboratory column and microfluidic studies have shown that drainage and imbibition in unsaturated systems promote colloid mobilization by the moving GasWater Interfaces (GWI) (Cheng \& Saiers, 2009; Lazouskaya et al., 2011, 2013; Saiers \& Lenhart, 2003). Column breakthrough curves have shown that pronounced colloid mobilization during imbibition than drainage (Cheng \& Saiers, 2009; Flury \& Aramrak, 2017; Zhuang, Tyner \& Perfect, 2009; Aramrak, Flury, Harsh, \& Zollars, 2014). The repulsive capillary force exceeds adhesion force and because of contact angle hysteresis, smaller capillary force exist at advancing interface resulting in less mobilization during drainage. Conversely, visualization experiments on capillary channels reveal comparatively higher mobilization by the advancing interface rather than the receding interface (Aramrak, Flury \& Harsh, 2011; Lazouskaya et al., 2013). Strength of colloid attachment on SWI might be contributing to the above contradicting behavior. Visualization study considering different force conditions on a deposited colloid would help to clear the inconsistency in the previous results.

Therefore, the objective of this work is to explore the effect of ionic strength on colloid mobilization during drainage and imbibition in a micromodel. The visualization study was conducted on retention and remobilization of colloids during transient flow conditions at two different ionic strength.

\section{MATERIALS AND METHODS}

Carboxylate Modified Polystyrene (CMPS) latex mono-spheres was employed in the experiments with diameter of $5-\mu \mathrm{m}$ and particle density of $1.05 \mathrm{~g} / \mathrm{cm}^{3}$ (MAGSPHERE INC., Pasadena, CA). $0.5 \%$ colloid suspensions were prepared by diluting the stock solution (10\% solids) with brine solution. The ionic strength of brine solution was changed by adding $\mathrm{NaCl}$ in to deionized water to obtain $1 \mathrm{mM}$ and $100 \mathrm{mM}$ salinity. The $\mathrm{pH}$ of the colloid suspension was maintained as 10 by adding $0.1 \mathrm{M} \mathrm{NaOH}$. Colloid suspension was sonicated in a water bath for 30 minutes prior to each experiment using ultrasonic processor (SONICS, Vibra cell) to achieve dispersion. The zeta potential of the colloids in brine solutions was measured by a zetasizer (Nano ZSP, Malvern Panalytical, Southborough, MA) at $22^{\circ} \mathrm{C}$ and was obtained as $-10.40 \&-5.28 \mathrm{mV} . \mathrm{CO}_{2}$ gas was used 
as the non-wetting phase in drainage and imbibition studies.

The micromodel used in the experiments was fabricated by Micronit Microfluidics $\mathrm{BV}$ on glass plates to represent porous media. The etched area of the micromodel was measured $20 \mathrm{~mm} \times 10 \mathrm{~mm}$ with an etch depth of $20-\mu \mathrm{m}$. The surface of the microfluidic channel was hydrophilic with an average contact angle $20^{\circ}$. The pore volume, porosity and permeability of the micromodel are $2.3 \mu \mathrm{L}, 0.58$ and 2.5 Darcy, respectively. The micromodel placed inside the holder along with the connections was placed on a microscope stage (Leica Z6, APO).

The experimental set-up used in this study is shown in Figure 1. All the experiments were performed in three stages. The first stage was to saturate the micromodel with colloids in brine solution using a syringe pump (Kats Scientific, NE-1010). Images of micromodel at several locations were captured using a high-resolution camera (Leica MC170) attached to the microscope. The second stage involved the mobilization of the attached colloids by injecting $\mathrm{CO} 2$ at constant pressure of $10 \mathrm{kPa}$ using an ISCO pump (Teledyne ISCO $500 \mathrm{HP}$ ) and a high-sensitivity diaphragm-sensing pressure-reducing regulator (Swagelok KLF1CFA412A20000 PR regulator) through the outlet port. A commercial CO2 cylinder (Buzwairgas, 99.99\%) was supplied the $\mathrm{CO}_{2}$ gas to the ISCO pump. Maintaining constant pressure, water drainage was initiated by withdrawing water at a constant rate of $50 \mu \mathrm{L} / \mathrm{min}$ using the syringe pump connected at inlet port of the micromodel. The real time visualization of colloid mobilization from SWI was recorded as videos and the images were captured after attaining steady state conditions. The third stage involved the remobilization of the colloids from GWI by initiating imbibition. Colloid free brine solution was injected into the micromodel using another syringe pump connected through the outlet port with a three-way valve. The mobilization of colloids observed and recorded using the camera during and after imbibition.

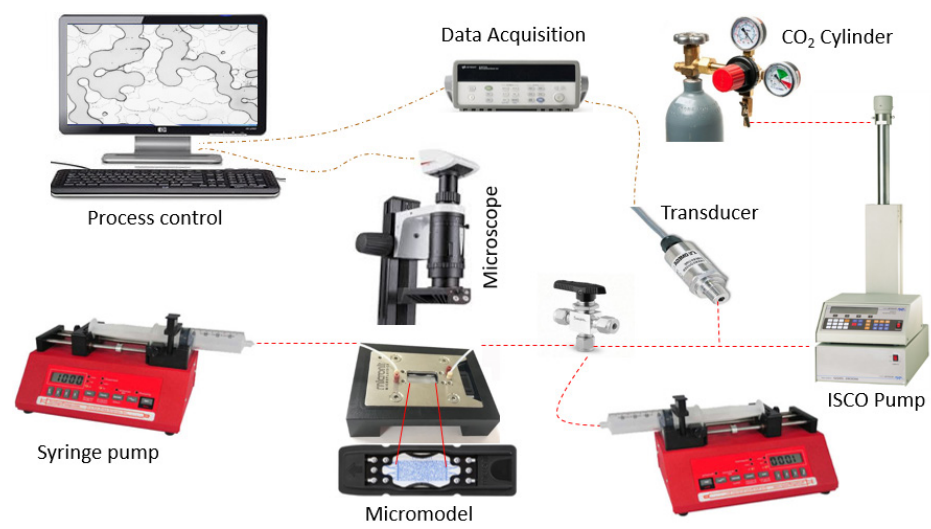

Figure 1: Experimental set-up

\section{RESULTS AND DISCUSSION}

\subsection{Colloid Interaction in Saturated Systems}

To examine the role of ionic strength on colloid interaction in saturated porous media, colloid transport experiments were performed at two different ionic strengths; $1 \mathrm{mM}$ and $100 \mathrm{mM}$ of $\mathrm{NaCl}$. The images of the micromodel after first stage are shown in Figure 
2 indicate the colloid interaction with other colloids and SWI. The DLVO interaction energies of colloids interacting with other colloids and SWI are calculated as sum of van der Waals and electrostatic forces. The measured zeta potential values are used at two ionic strength conditions. The calculated energy profiles plotted against separation distances and is given in Figure 3.

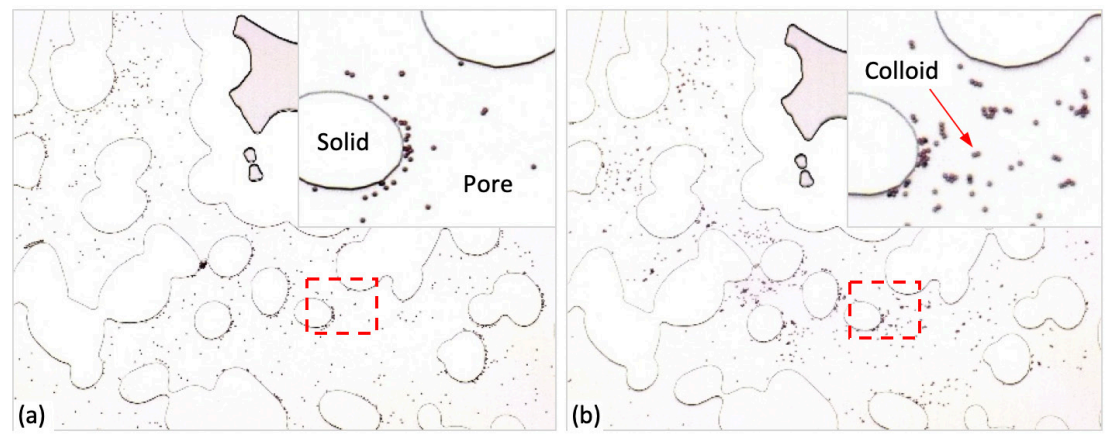

Figure 2: Images of Micromodel saturated with colloids in brine at ionic strength (a) 1 $\mathrm{mM}$ and (b) $100 \mathrm{mM}$

Under saturated conditions, colloid can either attach to SWI or aggregate to form colloid clusters and strain in small pore throats. The aggregation of colloid was observed more at higher ionic strength, whereas attachment on SWI occur irrespective of the ionic strength. Although the DLVO profile shows an energy barrier for colloid interaction with SWI at lower ionic strength, the attachment occurs at a separation distance smaller than $5 \mathrm{~nm}$ where primary energy minimum exist (Figure 3). The dispersed colloids in the pore space at lower ionic strength can be explained with the interaction energy profile, where the primary energy minimum exist at very short separation distance. The collision of colloids with previously attached colloids on SWI allow them to interact at these short separation distance and aggregate near the solid surfaces as observed from Figure 2a. Some colloids were attached at the bottom of the micromodel, as the interaction is favorable.

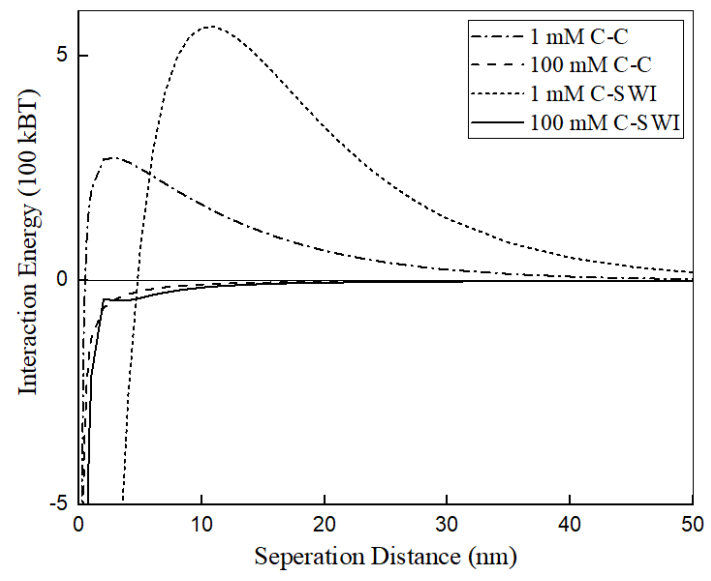

Figure 3: Calculated DLVO energy curve for interaction of colloids with other colloids (C-C) or SWI (C-SWI) at two ionic strengths 


\subsection{Colloid Mobilization during Drainage}

The second stage was started by injecting $\mathrm{CO} 2$ at constant pressure and withdrawing pore water at a flow rate of $50 \mu \mathrm{L} / \mathrm{min}$. Figure 4 shows the images of micromodel captured after attaining steady state $\mathrm{CO}_{2}$ flow during drainage at two ionic strength. As the interface invade the pore, the porous media was filtered by capturing deposited colloids on GWI as observed from Figure 4. The mobilized colloids remain attached on GWI and were either transported with moving GWI or retained in the porous media with stationary interface. Nevertheless, the random movement of colloids on the interface together with hydrodynamic drag forces rearrange the colloids towards Gas-Water-Solid Interfaces (GWSI) and physically strain there. Further invasion of GWI during drainage was resulted in thin film straining. In addition, colloids are also observed in the gas phase at higher ionic strength (Figure $4 \mathrm{~b}$ ) indicate thin film attachment at top/bottom of the micromodel. The excess particles on GWI shift towards GWSI at top/bottom of the micromodel and retained in thin films as the interface invade the pore. This film retention was observed only at higher ionic strength condition.

The force balance of deposited colloid at GWSI was considered to predict the mobilization from SWI. The adhesion force between the colloids and SWI (DLVO forces) was estimated to be $-3 \times 10^{-9}$ and $-1.2 \times 10^{-8} \mathrm{~N}$ for $1 \mathrm{mM}$ and $100 \mathrm{mM}$ ionic strength cases, respectively. The negative sign indicates attraction towards SWI. The drag force on partially saturated media is trivial compared to other forces (Lazouskaya et al., 2013; Shang, Flury, Chen \& Zhuang, 2008). The maximum capillary force determined using Equation 1 (Lazouskaya et al., 2013) was $5.5 \times 10^{-8}$ and $-1.7 \times 10^{-6}$ for drainage and imbibition front, respectively. Schematic of forces acting on colloid at drainage and imbibition front are shown in Figure 5.

$$
F_{c}=2 \pi r \sigma \sin \varphi \sin (\theta-\varphi)
$$

where $r$ is the radius of colloid, $\sigma$ is the surface tension, $\theta$ is the colloid contact angle and $\varphi$ is the angle determining position of GWI on colloid surface.

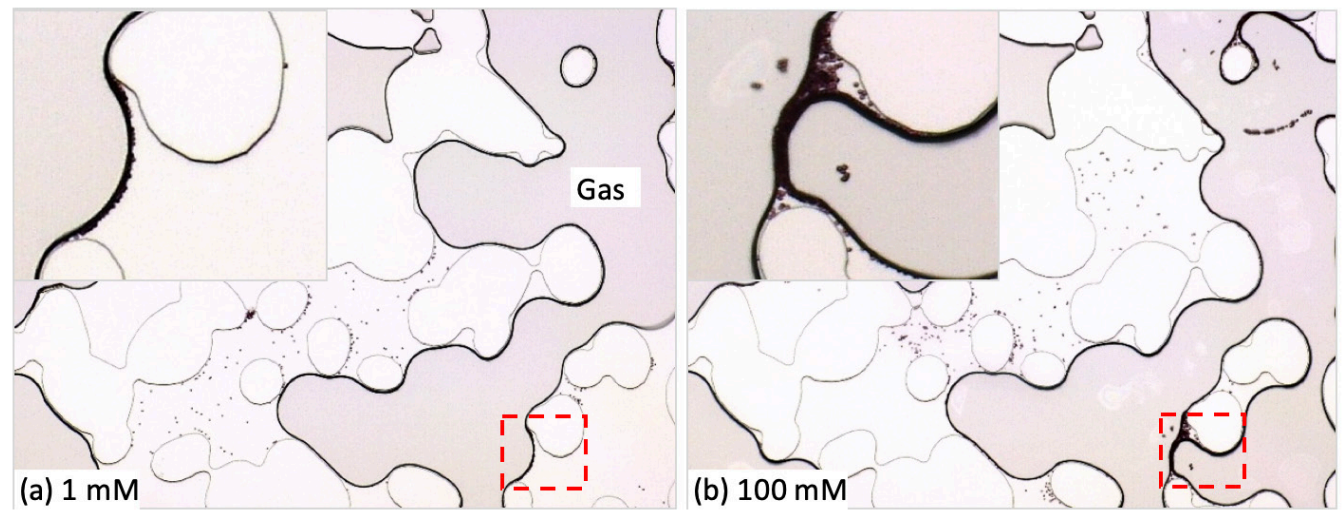

Figure 4: Images of Micromodel after injecting CO2. At lower ionic strength colloids were mobilized by moving GWI while at higher ionic strength, colloids were also retained in thin water films 
(a)

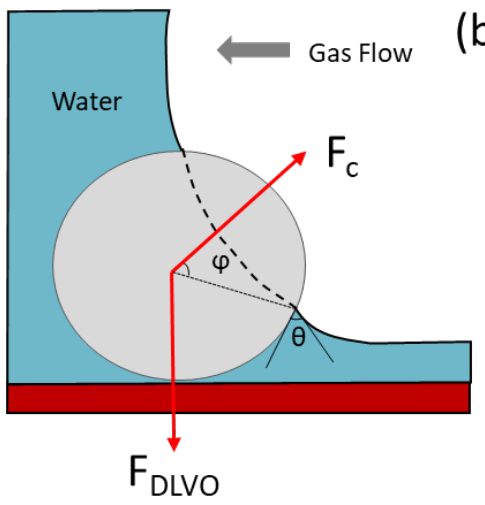

(b)

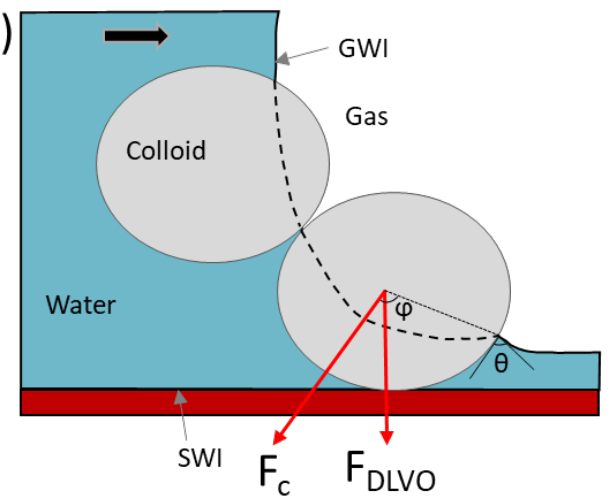

Figure 5: Schematic of forces acting on colloids at GWI: (a) drainage front (b) imbibition front

The above force calculations indicate the lifting of colloids from SWI by the capillary force associated with drainage front for two cases. This is consistent with the reported mobilization of colloids from a surface by capillary forces. Although deposited colloids were mobilized during drainage, the transport occur only with moving GWI. The trapped colloids at stationary gas interfaces can be only mobilized if transients in flow occur.

The colloids more than the GWI capacity shift to GWSI and thin film attachment occur with the advancing interface at higher ionic strength due to the higher adhesion forces, whereas at lower ionic strength those colloids were released back to bulk water. Therefore, breakthrough of colloids at lower ionic strength will be more compared to higher ionic strength due to lower retention on GWSI and thin films.

\subsection{Colloid Mobilization from GWI during Imbibition}

At the end of second stage, brine was injected into the micromodel at similar flow rate to initiate third stage. The displacement of gas by water (i.e., imbibition) resulted in remobilization of colloids retained on GWI. The advancing front of GWI transports the colloids along with the interface, whereas the receding front releases the excess colloids back to bulk water at lower ionic strength and reattach on SWI at higher ionic strength as shown in Figure $6 \& 7$. The excess colloids shifted towards GWSI released from the interface due to the horizontal component of the capillary force (Figure 5b). The comparatively lower adhesion forces of colloids at lower ionic strength transport them through the porous media and can deposit on SWI downstream. It is likely that higher ionic strength increase the adhesion force and pose greater affinity towards SWI resulting in reattachment immediately after released from GWI (Figure 7). Thereby reduce the colloid breakthrough after imbibition at higher ionic strength rather than the expected increased release. Our results suggest that the mobilization and retention of colloids were affected by the ionic strength as the adhesive forces play an important role in the detachment of colloid. 


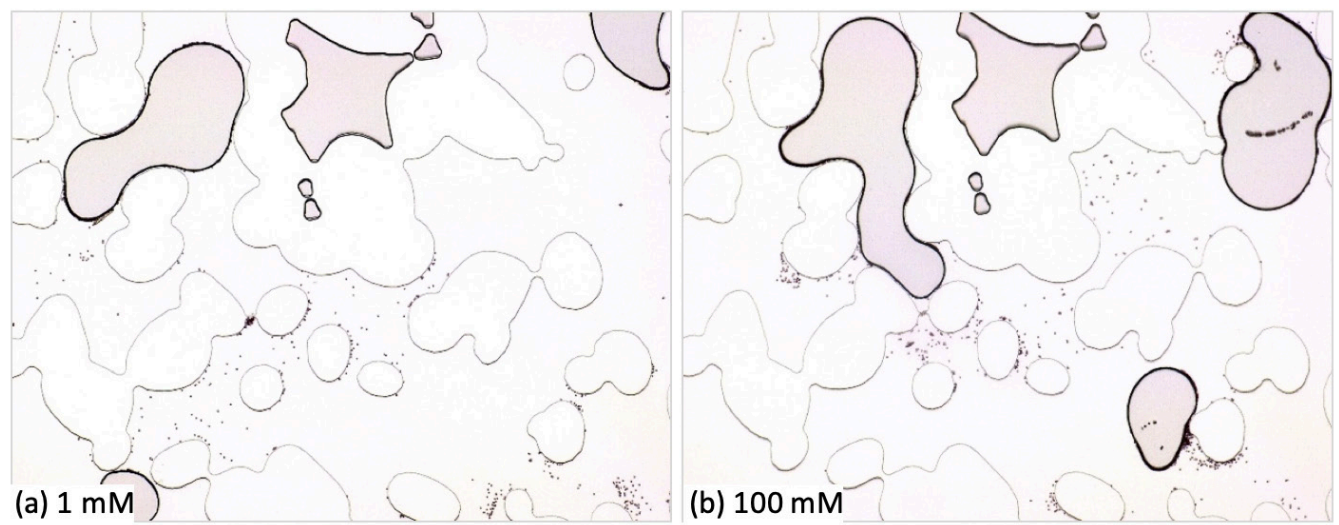

Figure 6: Images of Micromodel after imbibition. At lower ionic strength colloids were released back to bulk water while at higher ionic strength colloids were reattached on solid surfaces

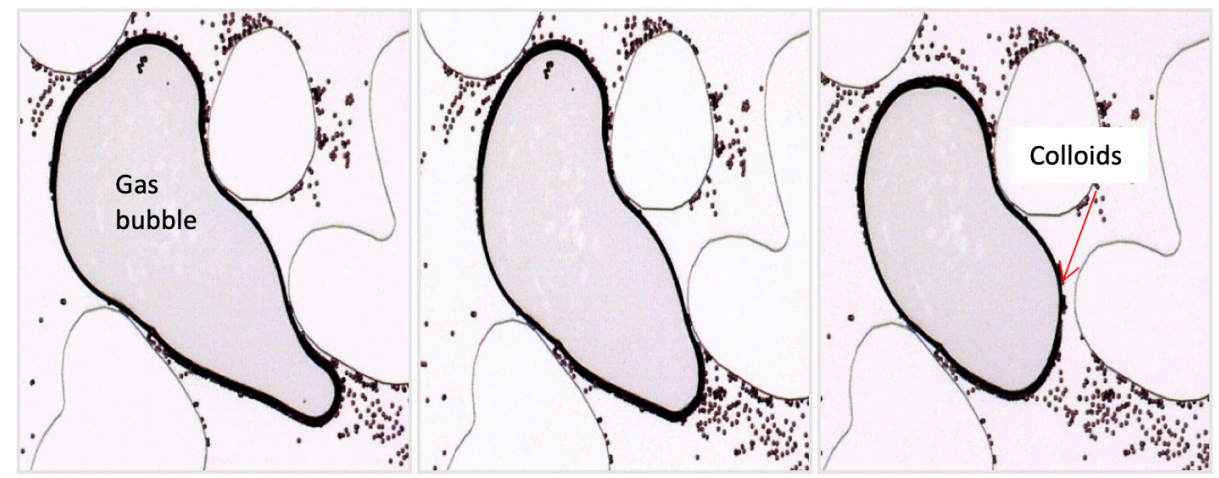

Figure 7: Snapshots of dissolution of Gas bubble $\left(\mathrm{CO}_{2}\right)$ during imbibition at higher ionic strength. The excess particles on GWI reattach on SWI (bottom of the micromodel), as the adhesive forces were greater

\section{CONCLUSION}

This study shows that increasing the ionic strength can be an effective way to control colloid transport and remobilization in porous media. The main conclusions from this study are as follows:

1. The interaction of colloids with other colloids and SWI increases with increase in ionic strength of the solution.

2. Although colloid mobilization by GWI was observed at all ionic strength conditions, immobilization at thin films and stationary GWSIs are more at higher ionic strength due to the higher adhesive forces.

3. Remobilization of colloids from GWI during imbibition was resulted in transport of colloids in the porous media and reattachment on SWI at higher ionic strength.

4. Greater release of contaminants or pathogens attached on SWI or GWI can be expected during drainage or imbibition at lower ionic strength than at higher ionic strength. 


\section{ACKNOWLEDGMENT}

This publication was made possible by partial funding from NPRP grant \# NPRP8594-2-244 from the Qatar National Research Fund (a member of Qatar Foundation). Any opinions, findings, and conclusions or recommendations expressed in this material are those of the authors and do not necessarily reflect the views of funding agencies.

\section{REFERENCES}

Aramrak, S., Flury, M., Harsh, J. B. \& Zollars, R. L. (2014). Colloid mobilization and transport during capillary fringe fluctuations. Environmental Science \& Technology, 48(13), 7272-7279.

Aramrak, S., Flury, M. \& Harsh, J. B. (2014). Detachment of Deposited Colloids by Advancing and Receding Air-Water Interfaces. Langmuir, 27(16), 9985-9993.

Cheng, T. \& Saiers, J. E. (2009). Mobilization and transport of in situ colloids during drainage and imbibition of partially saturated sediments. Water Resources Research, 45(8), 1-14. https:// doi.org/10.1029/2008WR007494.

Crist, J. T., Zevi, Y., Mccarthy, J. F., Throop, J. A. \& Steenhuis, T. S. (2005). Transport and Retention Mechanisms of Colloids in Partially Saturated Porous Media. 4 (2000), 184-195.

Flury, M. \& Aramrak, S. (2017). Role of air-water interfaces in colloid transport in porous media: A review. Water Resources Research, 53(7), 5247-5275.

Gao, B., Steenhuis, T. S., Zevi, Y., Morales, V. L., Nieber, J. L., Richards, B. K. ... \& Parlange, J. (2008). Capillary retention of colloids in unsaturated porous media. Water Resources Research, 44(4).

Lazouskaya, V., Wang, L.-P., Gao, H., Shi, X., Czymmek, K. \& Jin, Y. (2011). Pore-scale investigation of colloid retention and mobilization in the presence of a moving air-water interface. Vadose Zone Journal, 10(4), 1250-1260.

Lazouskaya, V., Wang, L.-P., Or, D., Wang, G., Caplan, J. L. \& Jin, Y. (2013). Colloid mobilization by fluid displacement fronts in channels. Journal of Colloid and Interface Science, 406, 4450 .

Mesticou, Z., Kacem, M. \& Dubujet, P. (2014). Influence of ionic strength and flow rate on silt particle deposition and release in saturated porous medium: experiment and modeling. Transport in Porous Media, 103(1), 1-24.

Mesticou, Z., Kacem, M. \& Dubujet, P. (2016). Coupling effects of flow velocity and ionic strength on the clogging of a saturated porous medium. Transport in Porous Media, 112(1), $265-282$.

Mitropoulou, P. N., Syngouna, V. I. \& Chrysikopoulos, C. V. (2013). Transport of colloids in unsaturated packed columns: Role of ionic strength and sand grain size. Chemical Engineering Journal, 232, 237-248. https://doi.org/10.1016/j.cej.2013.07.093.

Molnar, I. L., Johnson, W. P., Gerhard, J. I., Willson, C. S. \& O’Carroll, D. M. (2015). Predicting colloid transport through saturated porous media: A critical review. Water Resources Research, 51(9), 6804-6845.

Pazmino, E., Trauscht, J. \& Johnson, W. P. (2014). Release of colloids from primary minimum contact under unfavorable conditions by perturbations in ionic strength and flow rate. Environmental Science \& Technology, 48(16), 9227-9235.

Saiers, J. E. \& Lenhart, J. J. (2003). Colloid mobilization and transport within unsaturated porous media under transient-flow conditions. 39(1). https://doi.org/10.1029/2002WR001370. 
Shang, J., Flury, M., Chen, G. \& Zhuang, J. (2008). Impact of flow rate, water content, and capillary forces on in situ colloid mobilization during infiltration in unsaturated sediments. Water Resources Research, 44(6), 1-12. https://doi.org/10.1029/2007WR006516.

Sirivithayapakorn, S. \& Keller, A. (2003). Transport of colloids in unsaturated porous media : A pore-scale observation of processes during the dissolution of air-water interface. 39(12). https://doi.org/10.1029/2003WR002487.

Syngouna, V. I. \& Chrysikopoulos, C. V. (2015). Experimental investigation of virus and clay particles cotransport in partially saturated columns packed with glass beads. Journal of Colloid and Interface Science, 440, 140-150.

Torkzaban, S., Tazehkand, S. S., Walker, S. L. \& Bradford, S. A. (2008). Transport and fate of bacteria in porous media: Coupled effects of chemical conditions and pore space geometry. Water Resources Research, 44(4).

Zevi, Y., Dathe, A., Gao, B., Zhang, W., Richards, B. K. \& Steenhuis, T. S. (2009). Transport and retention of colloidal particles in partially saturated porous media: Effect of ionic strength. Water Resources Research, 45(12).

Zhuang, J., Goeppert, N., Tu, C., McCarthy, J., Perfect, E. \& McKay, L. (2010). Colloid transport with wetting fronts: Interactive effects of solution surface tension and ionic strength. Water Research, 44(4), 1270-1278.

Zhuang, J., Tyner, J. S. \& Perfect, E. (2009). Colloid transport and remobilization in porous media during infiltration and drainage. Journal of Hydrology, 377(1-2), 112-119. https://doi. org/10.1016/j.jhydrol.2009.08.011. 